\title{
Ensino Remoto na Educação Pública de Nazarezinho - PB: Desafios Docentes
}

\section{Cleberson Vieira de Araújo ${ }^{1}$, Clebianne Vieira de Araújo², Guilherme Amisterdan Correia Lima ${ }^{3}$}

${ }^{1}$ Programa de Pós - Doutorado em Política Educativa, Estudos Sociais e Culturais CENID/ México.

\author{
${ }^{2}$ Mestrada em Educação Profissional e Tecnológica - ProfEPT, IFPB. \\ ${ }^{3}$ Especialização em Análise Regional e Ensino de Geografia - Universidade Federal de \\ Campina Grande, UFCG. \\ cleberson.historiador@gmail.com, clebianne@hotmail.com, \\ amisterdan87@gmail.com
}

\begin{abstract}
It is up to the school to develop practices as a way of serving contemporary society. Aimed at basic education, this work has the general objective of: Analyzing the impact of remote education in the educational scope of the municipality of Nazarezinho, identifying the limits and challenges for carrying out network activities (online). As specific objectives, it counts on: Knowing the strategies and resources used by teachers in carrying out remote activities; List the main difficulties regarding the development and execution of activities and student participation; Discuss the importance of educational technologies in the teaching-learning process. Through the qualitative and exploratory approach, the research was based on the selection of theoretical frameworks and data collection through questionnaires produced in Forms, a complement to Google, and applied to 44 teachers from the municipal and state network of the municipality. The research enabled a reflection on the directions of the process of using multiple modalities as a way of producing knowledge and attending to the teaching-learning process.
\end{abstract}

Resumo. À escola cabe desenvolver práticas como forma de atender a sociedade contemporânea. Voltado à educação básica, esse trabalho tem por objetivo geral: Analisar o impacto do ensino remoto no âmbito educacional do município de Nazarezinho, identificando os limites e desafios para a realização das atividades em rede (online). Já enquanto objetivos específicos conta com: Conhecer as estratégias $e$ recursos utilizados pelos docentes na realização das atividades remotas; Elencar as principais dificuldades quanto ao desenvolvimento e execução das atividades e a participação dos estudantes; Discutir a importância das tecnologias educacionais no processo de ensino-aprendizagem. Por meio da abordagem qualitativa e de natureza exploratória, a pesquisa foi fundamentada com seleção de referenciais teóricos e coleta de dados por meio de questionários produzidos no Forms, complemento do Google, e aplicados a 44 professores da rede municipal e estadual do município. A pesquisa possibilitou uma reflexão acerca dos direcionamentos do processo de uso de múltiplas modalidades como forma de produzir conhecimento e atender ao processo de ensinoaprendizagem. 


\section{Introdução}

A educação permanece envolta em constantes mudanças e adaptações como forma de atender a sociedade contemporânea.

Com múltiplas modalidades, que se encontram na tarefa de produzir conhecimento, a educação segue agregando novas formas de fazer para atender a um público cada vez mais exigente.

Momentos de indefinição podem se mostrar como terreno fértil no fazer educacional proporcionando novas formas e meios de ensinar e aprender e, isso acorre em meio à pandemia do coronavírus onde professores e alunos passam a resinificar a educação de forma remota e agora, a tecnologia tão presente no cotidiano é definitivamente usada em favor da educação.

Em um processo vasto que acometeu o mundo inteiro, atingiu também os rincões e pequenos Municípios a exemplo de Nazarezinho - Paraíba, onde os docentes foram obrigados a se reinventarem para a educação não parar.

Logo, esse trabalho tem por objetivo geral: Analisar o impacto do ensino remoto no âmbito educacional do município de Nazarezinho, identificando os limites e desafios para a realização das atividades em rede (online). Já enquanto objetivos específicos conta com: Conhecer as estratégias e recursos utilizados pelos docentes na realização das atividades remotas; Elencar as principais dificuldades quanto ao desenvolvimento e execução das atividades e a participação dos estudantes; Discutir a importância das tecnologias educacionais no processo de ensino-aprendizagem.

Esse trabalho se faz importante por refletir sobre uma realidade tão atual, a educação remota em tempos de pandemia, a partir da experiência vivenciada por professores da rede pública do município de Nazarezinho - PB.

Assim, este trabalho está estruturado da seguinte forma: na seção 2, apresenta-se uma breve fundamentação teórica. $\mathrm{Na}$ seção 3, descreve-se a metodologia adotada. $\mathrm{Na}$ seção 4, apresentam-se os resultados obtidos, e uma discussão acerca da educação remota a partir de um questionário aplicado. As conclusões são devidamente apresentadas na seção 5.

\section{A "novidade" da educação remota e a EAD}

A educação a distância não é uma novidade e remonta a ações realizadas há séculos atrás onde a tentativa de comunicar para ensinar já era colocada em prática.

Porém, tendo em vista à pandemia do coronavírus passou-se a adotar a educação remota (que possui elementos da EAD), em muitos Estados e Municípios, como forma de manutenção de vínculos entre escolas, alunos e a professores.

E, de uma vez por todas, a Educação a Distância passou a entrar no debate cotidiano da educação como uma "novidade" o que demonstra o atraso em utilizar ferramentas tecnológicas e metodologias diferenciadas para encurtar distâncias também no aspecto educacional, e essa modalidade passou a ser testado e repensado, para continuar a existir o processo educacional, agora assentado em outras bases. 
A ideia básica de educação a distância é muito simples: alunos e professores estão em locais diferentes durante todo ou grande parte do tempo em que aprendem e ensinam. Estudando em locais distintos, eles dependem de algum tipo de tecnologia para transmitir informação e lhes proporcionar um meio para interagir [Moore; Kearsley, 2007, p. $1]$.

E, ao entender a ideia básica da Educação a Distância, entre tantos temas e novidades que vem sendo colocados em prática, não se poderia deixar de discutir a postura do aluno da Educação à Distância, agora distante do professor e com autonomia, e sobre o que é esperado desses quando é apontado como

Aquele que não tem condições de frequentar o ensino convencional o acesso ao ensino, além de ser apontada como uma alternativa de capacitação corporativa e em serviço. A experiência educacional nessa área tem comprovado que seu público-alvo é, em sua grande maioria, o aluno adulto que busca formação pessoal ou progressão profissional [Sartori, 2005, p. 141].

Já Belloni (2003) chama a atenção para autonomia e certa liberdade do estudante no processo de aprendizagem ao se autogerir nesse meio de autoaprendizagem com o mínimo de organização e habilidade de estudo. E o resultado é um acumulo de atividades em um contexto onde o alunado da educação básica nem sempre sabe se organizar para os estudos fora do ambiente escolar.

Vale salientar que os professores também não se encontram devidamente preparados, bem como a equipe escolar como um todo, para esse novo estágio da educação e, lacunas de formação passam a aparecer fortemente como indício de sucateamento educacional, não adaptação aos novos momentos impostos pela tecnologia e improviso com vistas ao oferecimento da tão desejada educação.

E, diante de tantas incertezas e medos, professores e alunos são surpreendidos com essa nova realidade batendo a porta em face da pandemia, onde Municípios e Estados passaram a adotar a educação remota como única alternativa viável a educação no momento, e, em Nazarezinho - Paraíba não foi diferente já que várias ferramentas passaram a ser usadas desde o Google Sala de Aula ate o Whatsapp passaram a estar a serviço da educação.

Portanto, a EAD precisa ser mais bem compreendida e ate mesmo agregada a contemporaneidade, para além do momento de crise. A dificuldade repousa na distância que se tem geralmente dessa modalidade de ensino e da formação precária de muitos professores que não passam por formações com frequência. Outra questão que chama a atenção não os vícios da educação presencial que se choca com a necessidade de autonomia no agir do aluno da EAD, ou mesmo em aulas remotas, fazendo com que a dependência do compromisso do aluno e o bom uso de sua liberdade, enquanto característica da Educação a Distância, deixe a desejar em todo esse processo. 


\section{Metodologia}

O presente trabalho consiste em uma pesquisa de caráter qualitativo e exploratório, no qual, buscou-se analisar o impacto do ensino remoto no âmbito educacional do município de Nazarezinho, identificando os desafios no uso das tecnologias voltadas ao ensino remoto, adotado durante a realidade atípica de pandemia.

A pesquisa apresentou um aspecto investigativo, com seleção de referenciais teóricos e coleta de dados por meio de questionários produzidos no Forms, complemento do Google. Os questionários estruturados, com perguntas fechadas, foram aplicados à rede municipal e estadual do município localizado no Alto Sertão paraibano.

Participaram da pesquisa 44 professores que lecionam diferentes componentes curriculares e atuam nos segmentos de educação infantil, ensino fundamental e ensino médio de quatro instituições de ensino onde as atividades remotas estão sendo adotadas para suprir as demandas da aprendizagem, a saber: Escola Municipal de Ensino Fundamental Amélia Maria Sarmento, Escola Municipal de Ensino Fundamental Maria do Carmo Pedroza Mendes, Escola Estadual de Ensino Fundamental Manoel Mendes e Escola Estadual de Ensino Médio Francisco Augusto Campos. A pesquisa permitiu que os docentes respondessem questões fundamentais, que se voltam à utilização das tecnologias em sala de aula e os desafios com a adoção do ensino remoto na atualidade.

\section{Resultados e Discussões}

Os professores que contribuíram com a pesquisa, possuem titulações variadas de graduação a doutorado (sendo $25 \%$ graduados, $65,9 \%$ especialistas, $6,8 \%$ mestres e $2,3 \%$ doutores). Desses, $52,3 \%$ afirmaram ter mais de 15 anos de experiência docente, enquanto $47,7 \%$ possuem até 15 anos de trabalho em sala de aula, fato que aponta uma variação em relação à equipe docente do município, que possuem professores com mais experiências e outros que estão ingressando na profissão.

Quando questionados se durante a sua formação pedagógica, obtiveram instruções ou conhecimentos suficientes a respeito das tecnologias e recursos educacionais aplicados ao ensino, $68,2 \%$ dos docentes afirmaram que não, como pode ser visto na figura 1 . Porém, 63,6\% afirmaram ter realizado capacitações, cursos de curta duração ou formações continuadas relacionadas às tecnologias educacionais (Figura 2). 


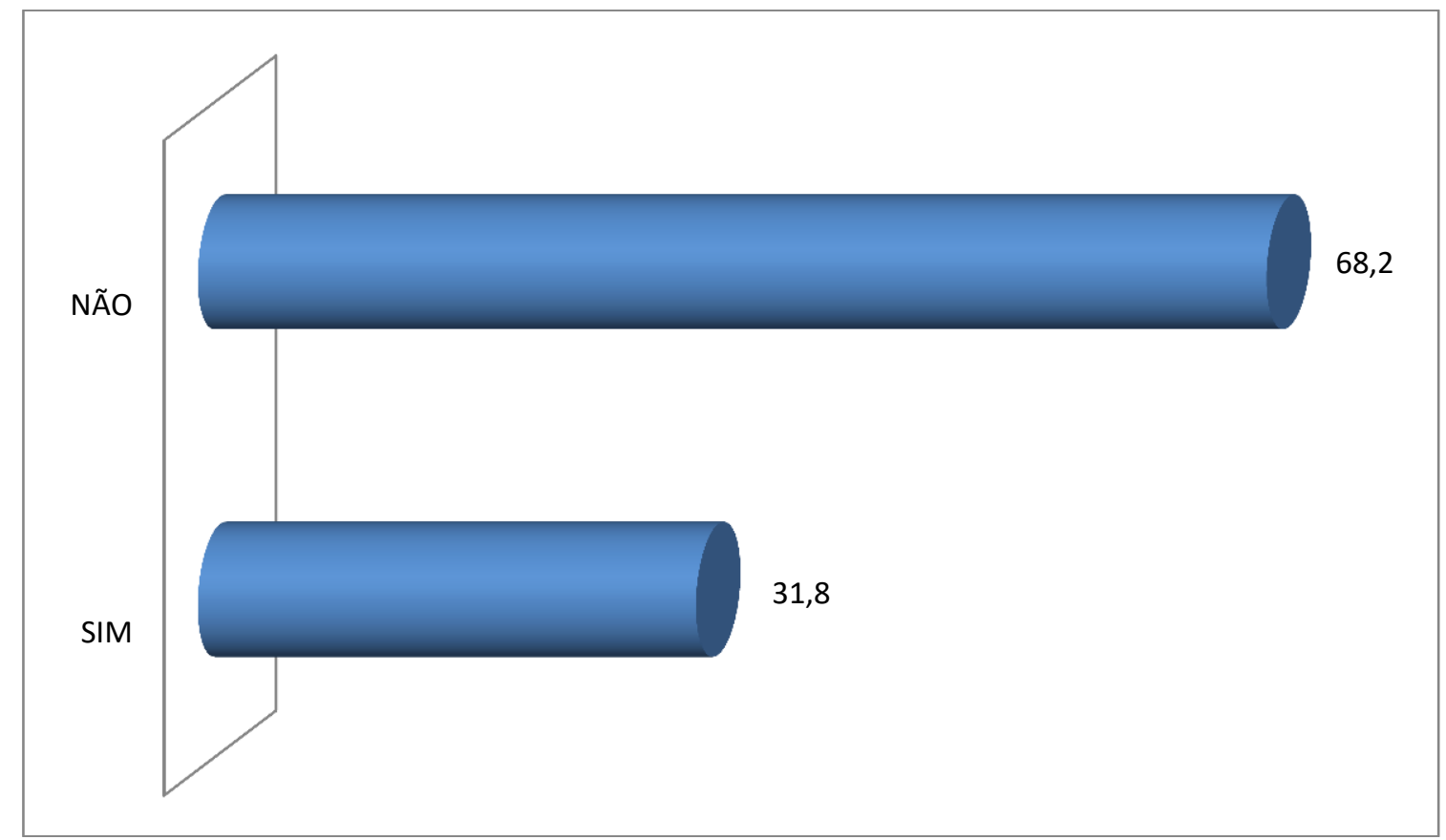

Figura 1. Instruções ou conhecimentos suficientes a respeito das tecnologias aplicadas ao ensino durante a graduação.

Fonte: Google Forms, 2020.

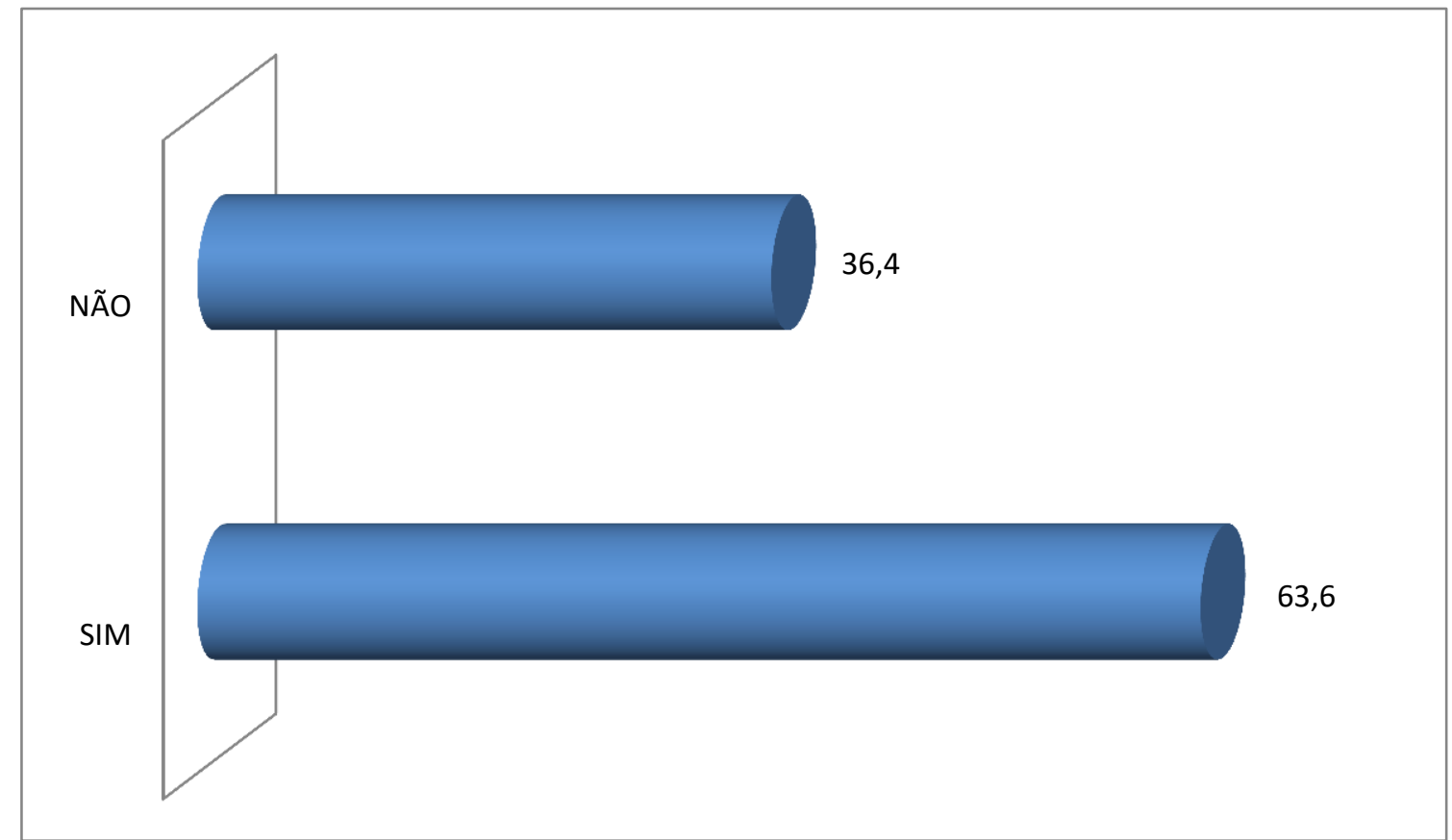

Figura 2. Realização de capacitação, cursos de curtas durações ou formações continuadas relacionadas às tecnologias em sala de aula.

Fonte: Google Forms, 2020.

Os dados apresentados nos gráficos demostram que grande parte dos professores analisados realizou cursos de aperfeiçoamentos voltados ao uso das tecnologias digitais 
da informação e comunicação (TDICs) em sala de aula, uma vez que não consideram as instruções recebidas nas graduações suficientes. Nesse sentido, Soares et al (2019, p.7), ressalta “ $[\ldots]$ a importância da incorporação das TDICs no currículo escolar e universitário, devido à necessidade em aprender a manejar e utilizar essas tecnologias de forma crítica e reflexiva", ou seja, a formação inicial deve oferecer as possibilidades de aprendizagem e interação com as tecnologias, as quais, são imprescindíveis na atualidade.

Em relação ao uso de tecnologias no contexto da sala de aula, apenas 4,5\% dos docentes analisados, afirmaram utilizá-las constantemente, 59,1\% utilizavam sempre que possível e $34,1 \%$ disseram que utilizavam esporadicamente, tal perspectiva, aponta que apesar do uso das tecnologias, ainda existia na sala de aula, forte recorrência aos métodos tradicionais, onde as TDICs não são utilizadas de modo crítico e ativo.

É comum encontrar professores que foram formados por meio de princípios e métodos tradicionais, reaplicando os mesmos métodos no momento do seu fazer docente [Souza, et al, 2018]. Porém, a nova realidade posta com a Pandemia COVID19, resultou na real necessidade de utilização constante das TDICs no processo de ensino-aprendizagem por meio de sistemas remotos de ensino, exigindo que os professores demostrem suas habilidades quanto ao uso de recursos tecnológicos. Mas será que os mesmos estão de fatos aptos a utilização de tais ferramentas?

Questionados sobre os recursos que estão sendo utilizados nas escolas do município em questão, 59,1\% dos docentes afirmaram que não conheciam os recursos que estão sendo utilizados pelas escolas, a exemplo do Google Classroom, Google Meet e Zoom, que permitem a interação dos professores com os estudantes por meio de atividades síncronas e assíncronas.

Essa informação demostra que os professores estão se deparando com outra realidade que lhe exige maiores cobranças em relação à utilização de estratégias e recursos. Tal questão, já era apontada por Teles, et al $(2019$, p. 3), ao afirmar que: "Hoje, demanda-se à formação de um indivíduo e um profissional criativo, autônomo, crítico, inovador, que possua as habilidades necessárias para não se ocupar apenas em executar mecanicamente o que é proposto, mas que consiga ir além, criando algo novo".

Inovar tem sido uma palavra de ordem no contexto atual de ensino, mas algumas lacunas precisam ser superadas para a obtenção dos bons resultados. Em relação às dificuldades dos docentes com a utilização dos recursos tecnológicos no ensino remoto de suas escolas (Figura 3), a maioria apontou a pouca prática com as ferramentas e os recursos utilizados, além da tarefa de auxiliar aos estudantes com a utilização dessas ferramentas, que se somam em alguns momentos a questões de ordem técnicas, a exemplo da não disponibilização de um bom serviço de internet. 


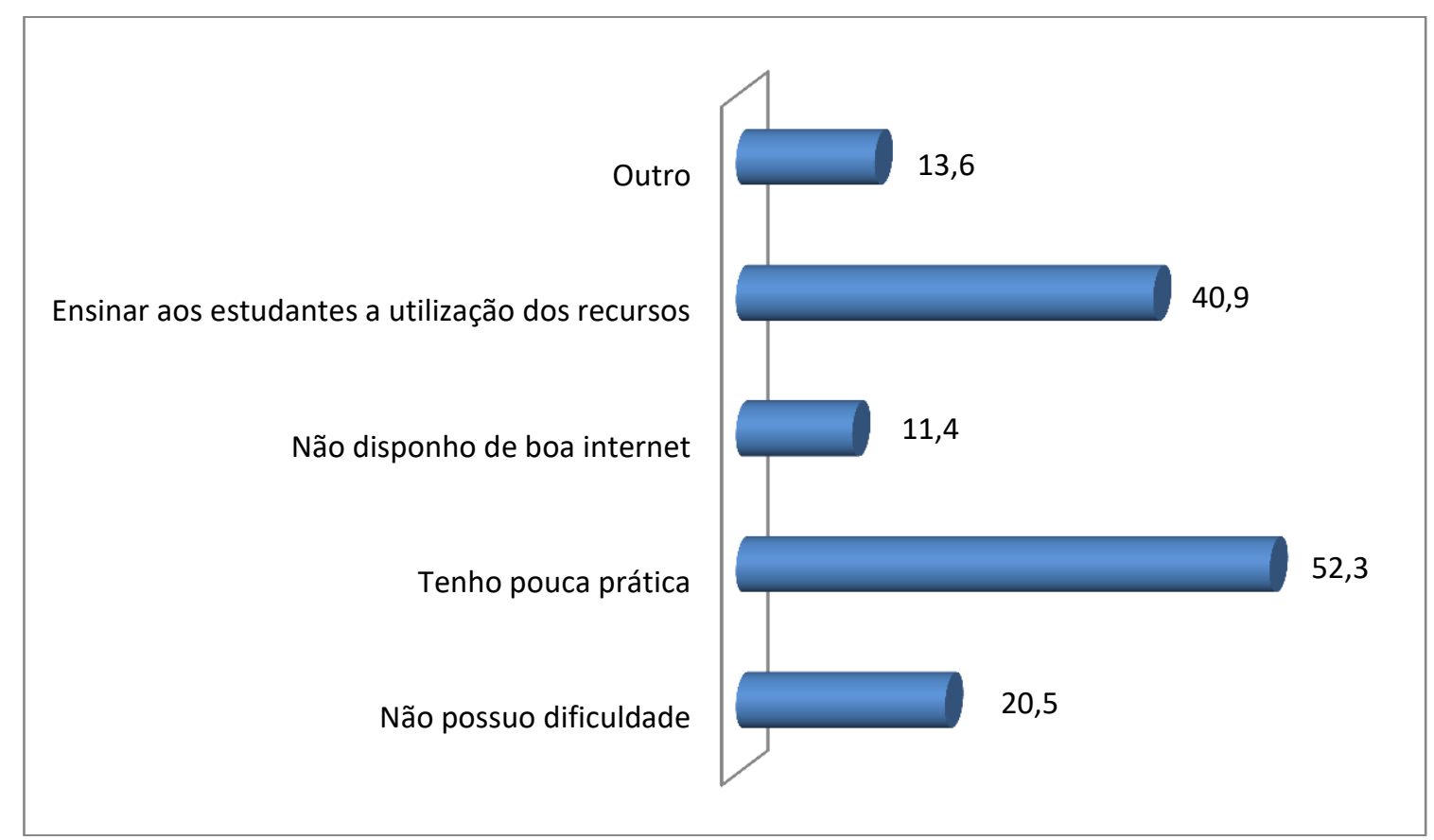

Figura 3. Dificuldades dos docentes em relação ao uso dos recursos tecnológicos no ensino remoto.

Fonte: Google Forms (2020).

Os aspectos apresentados no gráfico entram em conformidade com o pensamento de Souza et al (2018, p.473), onde: "Não é suficiente apenas fazer uso das tecnologias digitais no cotidiano escolar; o professor tem que estar preparado profissionalmente, disposto a pensar diferente, buscando inovações para mediação da construção do conhecimento". Assim, fica evidente a importância da formação continuada e o entendimento de que o educador necessita de constantes atualizações, capazes de atender as reais necessidades do contexto educacional.

Tais características apresentadas em relação às dificuldades com o uso das ferramentas tecnológicas contribuem para a situação descrita no último questionamento apresentado aos docentes: O aproveitamento dos conteúdos (Figura 4). 


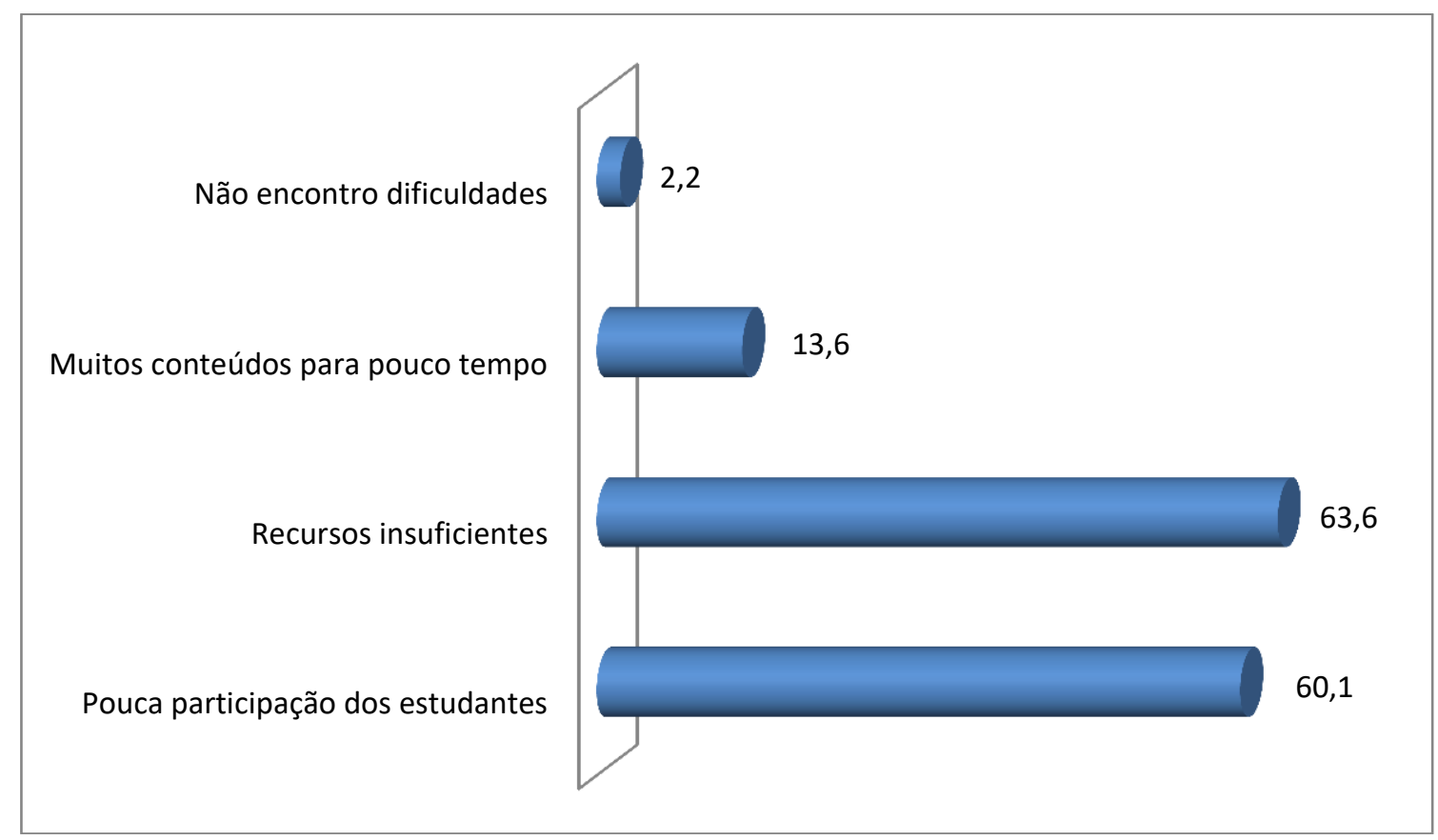

Figura 4. Dificuldades quanto aos conteúdos no ensino remoto.

Fonte: Google Forms (2020).

Observamos que $63,6 \%$ dos professores afirmam que os recursos utilizados ainda são insuficientes para a aprendizagem de determinados conteúdos e 60,1\% comprovam a pouca participação dos estudantes nas atividades remotas.

Tais fatores nos fazem refletir sobre o papel das tecnologias no contexto educacional, uma vez que como nos afirma Souza, et al (2018, p.470): “[...] a tecnologia não cria ambientes que excluem o professor, esse, deve tomar para si a tarefa de projetar o material didático e a dinâmica a ser utilizada no processo de ensino", para isso, tornase imprescindível que o professor se familiarize cada vez mais com as tecnologias digitais, sabendo que os recursos se submetem as suas ações, que dependerá de possibilidades, intenções e objetivos concretos.

\section{Conclusão}

A tecnologia que tanto encanta no cotidiano, quando aplicada a educação por vezes causa estranhamento e medo.

Assim, professores e alunos foram pegos de surpresa com essa nova realidade imposta pela pandemia fazendo a educação ser reinventada com formações elaboradas as pressas e plataformas implementadas sem aviso prévio.

$\mathrm{O}$ medo e as dificultardes se avolumavam fazendo com que, ate mesmo, os professores, ditos mais preparados, passassem a rever conceitos cristalizados e se renovar para com isso criar uma nova metodologia para melhor atender a alunos e alunas.

Logo, com estratégias que antes não eram utilizadas, e passaram a figurar no cotidiano dos professores em face pandemia, os docentes tiveram que se reinventar e mesmo aqueles que não se viam em meio a tecnologias buscaram fazer frente à 
dificuldade, quase que como um impositivo em face ao trabalho. Diante de tudo isso se mostrou clara a importância da tecnologia em todo esse processo, pois foi ela que tornou possível a educação, mesmo em tempos de distanciamento social.

Com isso, desafios e dificuldades enfrentadas, no município de Nazarezinho Paraíba, repetem-se também Brasil a fora apontando problemas com a internet, a falta de preparo, a novidade e a própria pandemia como motivos que podem levar ao afastamento de alunos e alunas, isso tudo associado a professores cansados e sobrecarregados com todo esse processo em curso.

Portanto, a educação coloca a prova pais, estudantes e professores em um novo momento educacional que muito pode ensinar a partir da experiência vivenciada. $\mathrm{O}$ novo, que assusta, também gera superação e novos frutos mediante o uso da tecnologia inusitada, ainda que essa estivesse presente há muito tempo, o que leva a reflexões profundas rumo à educação do futuro e o papel do professor em todo esse processo tecnológico.

\section{Referências}

Belloni, Maria Luiza. (2003) "Educação à distância". 3. ed. Campinas: Autores Associados.

Borges, R. P.; (2020) "Fundamento da Educação a Distância. Módulo 3". pp. 83-90. Natal: IFRN.

Moore, M. G.; Kearsley, G. (2007) "Educação a Distância: uma visão integrada". Tradução de Roberto Galman. São Paulo: Thomson Learning.

Sartori, Ademilde Silveira. (2005) "Educação superior à distância: gestão da aprendizagem e da produção de materiais didáticos impressos e on-line. Tubarão: Ed.: Unisul.

Soares, D. M. R; Et al. (2019) "Tecnologias Digitais nos Processos de Ensino e Aprendizagem dos Conteúdos Escolares: Compreensão dos(as) Licenciandos(as) da Disciplina Tecnodocência", In: CONGRESSO SOBRE TECNOLOGIAS NA EDUCAÇÃO (CTRL+E), 4. , 2019, Recife. Anais do IV Congresso sobre Tecnologias na Educação. Porto Alegre: Sociedade Brasileira de Computação, dec. p. 397-405.

Souza, J. D. de; Et al. (2018) "O Uso das Tecnologias Digitais nas Escolas do Município de Assú - RN”, In: CONGRESSO SOBRE TECNOLOGIAS NA EDUCAÇÃO (CTRL+E), 3, 2018, Fortaleza. Anais do III Congresso sobre Tecnologias na Educação. Porto Alegre: Sociedade Brasileira de Computação. p. 468-475.

Teles, G.; Et. al. (2019) "Docência e Tecnologias Digitais na Formação de Professores: Planejamento e Execução de Aulas por Licenciandos", In: CONGRESSO SOBRE TECNOLOGIAS NA EDUCAÇÃO (CTRL+E), 4. , 2019, Recife. Anais do IV Congresso sobre Tecnologias na Educação. Porto Alegre: Sociedade Brasileira de Computação, dec. p. 387-396. 